Article

\title{
An Advanced Shear Strength Criterion for Rock Discontinuities Considering Size and Low Shear Rate
}

\author{
Bowen Zheng ${ }^{1,2,3, *}$, Shengwen $\mathrm{Qi}^{1,2,3, * \mathbb{D}}$, Xiaolin Huang ${ }^{1,2,3}$, Songfeng Guo ${ }^{1,2,3}$, \\ Chonglang Wang ${ }^{4}$, Zhifa Zhan ${ }^{5}$ and Guangming Luo ${ }^{1,2,3}$ \\ 1 Key Laboratory of Shale Gas and Geoengineering, Institute of Geology and Geophysics, \\ Chinese Academy of Sciences, Beijing 100029, China; huangxiaolin@mail.iggcas.ac.cn (X.H.); \\ guosongfeng@mail.iggcas.ac.cn (S.G.); luoguangming@mail.iggcas.ac.cn (G.L.) \\ 2 Innovation Academy for Earth Science, Chinese Academy of Sciences, Beijing 100029, China \\ 3 College of Earth Science, University of Chinese Academy of Sciences, Beijing 100049, China \\ 4 Department of Civil \& Mineral Engineering, University of Toronto, Toronto M5S 1A4, Canada; \\ chonglang.wang@mail.utoronto.ca \\ 5 China Highway Engineering Consulting Corporation, Beijing 100089, China; zhanzhifa100@126.com \\ * Correspondence: zhengbowen@mail.iggcas.ac.cn (B.Z.); qishengwen@mail.iggcas.ac.cn (S.Q.); \\ Tel.: +86-010-8299-8660 (B.Z.); +86-010-8299-8055 (S.Q.)
}

Received: 8 May 2020; Accepted: 10 June 2020; Published: 14 June 2020

\begin{abstract}
The shear strength of the rock discontinuities under different shear rates is of great importance to evaluate the stability of rock mass engineering, which is remarkably influenced by the size effects induced by both the length and the undulated amplitude of discontinuities. An advanced shear strength criterion taking into account the size and the shear rate simultaneously was proposed. There is an advantage of the dimension unity in terms of the new shear strength criterion in comparison to previous related empirical equations. Additionally, it can be degraded into the International Society for Rock Mechanics (ISRM)-suggested Barton shear strength empirical equation on the peak shear strength of the rock discontinuities. Then, based on a new dynamic direct shear testing device on rock joints, the granite discontinuities with various lengths (200 $\mathrm{mm}$ to $1000 \mathrm{~mm}$ ) and undulated amplitudes ( $3 \mathrm{~mm}$ to $23 \mathrm{~mm}$ ) were designed to conduct direct shear tests under different low shear rates $(0 \mathrm{~mm} / \mathrm{s}$ to $1 \mathrm{~mm} / \mathrm{s})$ to verify the involved empirical equations. It was found that the results predicted by the new shear strength criterion agreed well with the experimental results. It was proved that the new shear strength criterion had a better applicability to characterize the shear strength of the rock discontinuities.
\end{abstract}

Keywords: rock mass engineering geomechanics; rock discontinuities; shear loading; strength assessment; size and shear rate effects; qualitative characterization

\section{Introduction}

Discontinuities commonly exist in the natural rock mass, occurring at different scales, such as the fault and the joint [1-4]. They are weak and discontinuous interfaces along which the failure and mobilization of the rock mass initiate under both gravity and earthquakes. Namely, the mechanical behavior of the rock mass is prominently influenced by the discontinuity [5-9]. In the past few decades, strong earthquakes have taken place all over the world, triggering thousands of co-seismic landslides. According to post disaster investigations, it was found that these co-seismic landslides were mainly controlled by discontinuities in the slope rock mass [10-12]. As a matter of fact, the instability of the rock mass under the earthquake mainly resulted from the dynamic response of the rock discontinuity, which interacted with the stress wave and further produced dynamic deformation and failure [13-15]. 
The key to evaluate the stability of the rock mass under an earthquake is to quantitatively describe the dynamic characteristics of the rock discontinuity, among which the dynamic shear strength is the most important property $[16,17]$.

Many researchers experimentally explored the shear characteristics of the rock discontinuities mainly taking into account the roughness and friction angle of the discontinuity, the compression strength of the rock as well as the normal stress [18-29]. It was found that the peak shear strength of the rock discontinuities increased with the values of these factors increasing. Due to the irregularity of the geometrical morphology of the rock discontinuities, it was often very difficult to theoretically characterize their roughness [30-36]. As a result, the shear strength of the rock discontinuities was usually characterized by empirical equations [18-22,24-29], among which the Barton shear strength empirical equation is now the ISRM-suggested equation and has been widely used to evaluate the stability of the rock mass under the gravity $[37,38]$.

Furthermore, Barton and Bandis [39,40] found that the peak shear strength of the rock discontinuities had an obvious size effect, i.e., the shear strength decreased with the increase of the discontinuity length along the shear direction (discontinuity length for short in the following). On this basis, they put forward the empirical equations of influence factors for shear strength considering the effect of discontinuity length. Nevertheless, it showed that the size effects of shear strength for the rock discontinuities were induced by not only the discontinuity length but also the discontinuity undulated amplitude of the shear contact surfaces (undulated amplitude for short in the following) [41-46]. An important finding was that the shear strength increased with the increase of the undulated amplitude.

However, in the above studies, the shear characteristics of the rock discontinuities were researched without taking into account the shear rate, while many experimental studies showed that it significantly influenced the shear strength of the rock discontinuities [47-57]. They indicated that the shear strength of the rock discontinuities, such as syenite and concrete discontinuities, increased with the shear rate, rising in the range of $0 \mathrm{~mm} / \mathrm{s}$ to $1 \mathrm{~mm} / \mathrm{s}$. Meanwhile, for the rock discontinuities such as sandstone and cement, the shear strength decreased with the shear rate's increase. Additionally, many researchers established an empirical equation (Table 1) to characterize the shear strength of the rock discontinuities under different shear rates [48,51,53-55].

Table 1. Empirical equations of shear strength considering the shear rate.

\begin{tabular}{|c|c|c|c|}
\hline Sample Type & Shear Rate $(\mathrm{mm} / \mathrm{s})$ & Empirical Equations & References \\
\hline Granite, Diamond-rock & $0 \sim 0.1$ & $\mu=\mu_{0}+A \log \left(\frac{B d_{\mathrm{c}}}{V}+1\right) \ldots$ (a) & [48] \\
\hline Cement & $0.02 \sim 0.8$ & $\tau=0.883 \sigma \tan \left(\varphi_{\mathrm{r}}+7.526 \alpha_{0}^{0.37}\right) V^{-0.032} \ldots(\mathrm{b})$ & [51] \\
\hline Cement mortar & $0.01 \sim 0.4$ & $\tau=0.982 \sigma \tan \left[\varphi_{\mathrm{b}}+4.970\left(J R C_{0}\right)^{0.475} \lg \left(\frac{J C S}{\sigma}\right)\right] \cdot V^{-0.06} \ldots$ (c) & [53] \\
\hline $\begin{array}{l}\text { Syenite, Sandstone, } \\
\text { Cement, Gypsum, } \\
\text { Concrete }\end{array}$ & $0.005 \sim 0.8$ & $\tau=\sigma \tan \left\{\log _{10}\left[\left(\frac{J C S}{\sigma}\right)^{J R C} \cdot\left(\frac{V_{0}}{V}\right)^{M}\right]+\varphi_{\mathrm{b}}\right\} \ldots(\mathrm{d})$ & [54] \\
\hline $\begin{array}{l}\text { Hot metamorphic } \\
\text { limestone, Chemically } \\
\text { deposited limestone }\end{array}$ & $0.0017 \sim 0.83$ & $\mu=\mu_{0}^{\prime}+a \ln (V)-b \ln \left(\sigma_{\mathrm{n}}\right) \ldots(\mathrm{e})$ & [55] \\
\hline
\end{tabular}

Symbols in Table 1: $\mu$ is the coefficient of sliding friction; $\mu_{0}$ is the constant coefficient of sliding friction; $\mu_{0}{ }^{\prime}$ is the friction coefficient when the normal stress is $1 \mathrm{MPa}$ and the shear rate is $1 \mathrm{~m} / \mathrm{s} ; A, B$ are constants related to the static friction strength; $a, b$ are material constants; $M$ is related to physical properties and the microgeometric morphology of the discontinuity; $d_{c}$ is the critical displacement, which is positively correlated with the discontinuity roughness; $V$ is the shear rate; $V_{0}$ is the constant shear rate; $\tau$ is the peak shear strength; $\sigma$ is the normal stress; $\varphi_{\mathrm{b}}$ is the basic friction angle of the discontinuity; $\varphi_{\mathrm{r}}$ is the residual friction angle; $\alpha_{0}$ is the undulated angle; JRC is the discontinuity roughness coefficient; $J R C_{0}$ is the initial roughness coefficient of the discontinuity; JCS is the discontinuity wall compressive strength. Note: In Equation (a), $\mu_{0}$ approximately equates $0.71, d_{c}$ is equal to $0.005 \mathrm{~mm}, A$ equates 0.02 , $B$ is equal to 1 [48]. In Equation (d), the units of $V_{0}$ and $V$ are $\mathrm{mm} / \mathrm{s}, V_{0}$ equates $1 \mathrm{~mm} / \mathrm{s}$ [54].

Among the empirical equations in Table 1, Equations (c) and (d) were improved based on the Barton shear strength empirical equation [53,54]. Nevertheless, there still existed some defects for these equations. First of all, the dimension unity could not be fulfilled in Equations (a), (b), (c) and (e) proposed by $[48,51,53,55]$. Thus, the physical meaning behind these equations was not clear. 
In addition, the size effects of both the discontinuity length and the undulated amplitude were not taken into account in Equations (a), (b), (c) and (e). Although the dimension unity and the size effect induced by the discontinuity length were considered in Equation (d) proposed by [54], the influence of the discontinuity undulated amplitude was ignored. Hence, these empirical equations have some limitations in the practical applications.

The purpose of this study is to establish a more feasible and reasonable criterion on peak shear strength of the rock discontinuities taking both the size and shear rate effects into account simultaneously. This paper is structured as follows. Section 1 reviews previous studies on the shear strength of the rock discontinuities and analyzes the limitations of these studies. Section 2 introduces the methods to establish the shear strength criterion and to design the verification laboratory tests. Section 3 shows the results in detail. Discussion and conclusions are given in Sections 4 and 5.

\section{Method}

\subsection{Establishment of the New Shear Strength Equation}

As mentioned in Section 1, compared with Equations (a), (b), (c) and (e) [48,51,53,55], Equation (d) proposed in [54] has an advantage of dimension unity, which can be used as the basis for establishing the new shear strength criterion of peak shear strength for the rock discontinuities considering both the size and shear rate effects.

Both the discontinuity roughness coefficient $(J R C)$ and the discontinuity wall compressive strength (JCS) are the fatal parameters in predicting the shear strength of the rock discontinuities $[21,37]$. Therefore, it is crucial to acquire the values of JRC and JCS accurately. In order to establish the new shear strength criterion taking into account the size and shear rate effects, first of all, it is indispensable to study the effects of the discontinuity length and the undulated amplitude on the values of JRC and JCS.

In previous studies, Barton and Bandis (1982) proposed the empirical equation of $J R C_{n}$ considering the effect of the discontinuity length on the shear strength [40]:

$$
J R C_{\mathrm{n}}=J R C_{0}\left(\frac{L_{\mathrm{n}}}{L_{0}}\right)^{-0.02 J R C_{0}},
$$

where $J R C_{\mathrm{n}}$ is the roughness coefficient of the shear contact surfaces for the discontinuity with the length of $L_{n} ; J R C_{0}$ is the roughness coefficient of the shear contact surfaces for the discontinuity of which length is $L_{0}$; In general, $L_{0}$ equates $100 \mathrm{~mm}$.

In Equation (1), the $J R C_{0}$ is calculated by the mathematical relation between $J R C_{0}$ and average value of entire secant angles, i.e., $\beta_{100 \%}$ for the shear contact surfaces of the irregular undulated discontinuity studied by [35], as shown in Equation (2):

$$
J R C_{0}=2.9206 \beta_{100 \%}^{0.7592}-3.1 .
$$

For discontinuity samples with regular sawtooth shapes, the $\beta_{100 \%}$ in Equation (2) can be degraded into the undulated angle of the shear contact surfaces for the discontinuity.

As mentioned in Section 1 , the $J R C$ value increased with increasing the undulated amplitude under the same discontinuity length condition $[43,45,46]$. However, the effect of the undulated amplitude was not taken into account in Equation (1), which needs to be improved. Hence, the maximal undulated amplitude was introduced as a correction parameter into Equation (1). The modified equation is assumed as follows:

$$
J R C_{\mathrm{n}}=J R C_{0}\left(\frac{L_{\mathrm{n}} / h_{\mathrm{n}}}{L_{0} / h_{0}}\right)^{-0.02 J R C_{0}},
$$

where $h_{\mathrm{n}}$ is the maximal undulated amplitude of the shear contact surfaces for the discontinuity when it has the length of $L_{n} ; h_{0}$ is the maximal undulated amplitude of the shear contact surfaces for the discontinuity with the length of $L_{0}$; In general, $L_{0}$ is equal to $100 \mathrm{~mm}$. 
Besides Equation (1), Barton and Bandis (1982) also put forward the empirical equation of JCS $\mathrm{n}$ considering the discontinuity length [40]:

$$
J C S_{\mathrm{n}}=J C S_{0}\left(\frac{L_{\mathrm{n}}}{L_{0}}\right)^{-0.03 J R C_{0}}
$$

where $J C S_{\mathrm{n}}$ is the wall compressive strength for the discontinuity as its length is $L_{\mathrm{n}} ; J C S_{0}$ is the wall compressive strength for the discontinuity with the length of $L_{0}$; In general, $L_{0}$ equates $100 \mathrm{~mm}$.

Substituting Equations (3) and (4) into Equation (d), we can obtain Equation (5) in which the new criterion of peak shear strength for discontinuities taking into account the size effects induced by the discontinuity length and the undulated amplitude as well as the shear rate effect was hypothesized:

$$
\tau=\sigma \tan \left\{\log _{10}\left[\left(\frac{I C S_{\mathrm{n}}}{\sigma}\right)^{J R C_{\mathrm{n}}} \cdot\left(\frac{V_{0}}{V}\right)^{M}\right]+\varphi_{\mathrm{b}}\right\} J S_{\mathrm{n}}=J C S_{0}\left(\frac{L_{\mathrm{n}}}{L_{0}}\right)^{-0.03 \pi R C_{0}}{ }_{J R C_{\mathrm{n}}}=J R C_{0}\left(\frac{L_{\mathrm{L}} / h_{\mathrm{n}}}{L_{0} / h_{0}}\right)^{-0.022 J R C_{0}} J R C_{0}=2.9206 \beta_{100 \%}^{0.7592}-3.1 .
$$

\subsection{Design of the Direct Shear Test}

As mentioned in Section 2.1, in order to verify the feasibility of the new shear strength criterion and explore the applicability of the previous empirical equations (Table 1), the granite discontinuity used to establish the first empirical equation in Table 1 was selected as the counterpart and to conduct direct shear tests in this section [47]. A series of indoor direct shear tests on granite discontinuity samples with various sizes and regular sawtooth shapes under different shear rates were designed, and the experiments were conducted by making full use of a new dynamic direct shear testing device on rock joints named as TFD-500/1000-JS in the Key Laboratory of Shale Gas and Geoengineering, Institute of Geology and Geophysics, Chinese Academy of Sciences, as shown in Figure 1 [58,59]. The internal dimension (i.e., length) of the shear box for the test platform ranges from $100 \mathrm{~mm}$ to $1000 \mathrm{~mm}$. The maximal shear rate can reach $1000 \mathrm{~mm} / \mathrm{s}$. All the index parameters of the new test platform are able to fulfill the requirement of dynamic direct shear tests $[37,60,61]$.
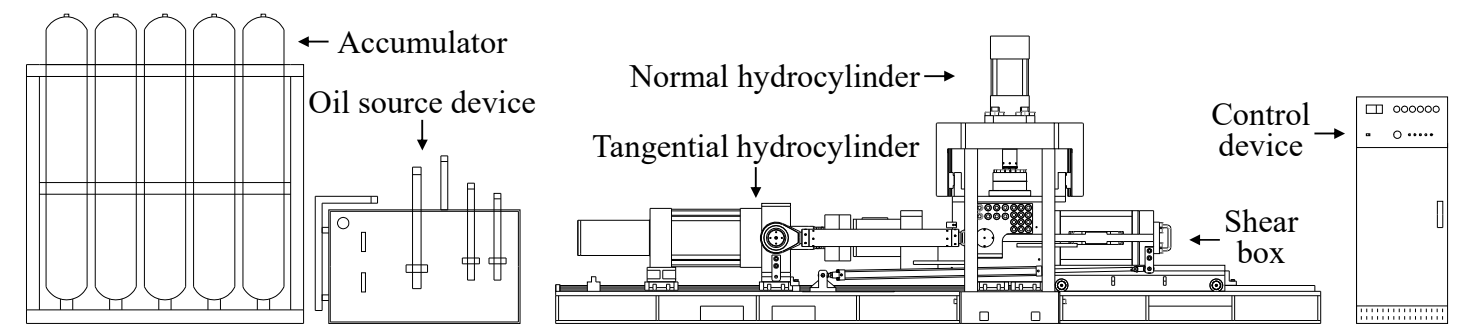

Figure 1. Hardware schematic of the test platform $[58,59]$.

Considering the size effects related to the discontinuity length and the undulated amplitude, the granite was cut and manufactured to artificial discontinuity samples with different dimensions and various regular sawtooth shapes by utilizing the digital control machine, as shown in Figure 2 . The sawtooth profile was regarded as the first-order irregularities on the discontinuities of which the surfaces were randomly rough due to the processing uncertainty [19]. There were line-shape asperities spreading along the direction of the sample width, which belonged to the second-order irregularities [19]. The uniaxial compressive strength and the basic friction angle of granite discontinuity samples were obtained respectively via the uniaxial compression test and the tilt test on flat granite discontinuity samples [21,37]. The geometric and strength parameters of granite discontinuity samples such as the sample length, undulated angle and amplitude, uniaxial compressive strength and basic friction angle were listed in Table 2.

Taking the shear rate ranges in the previous empirical equations (Table 1) into account, the indoor direct shear tests on granite discontinuity samples with various sizes (i.e., lengths from $200 \mathrm{~mm}$ to $1000 \mathrm{~mm}$ and undulated amplitudes from $3 \mathrm{~mm}$ to $23 \mathrm{~mm}$, as listed in Table 2) and regular sawtooth shapes under different low shear rates $(0 \mathrm{~mm} / \mathrm{s}$ to $1 \mathrm{~mm} / \mathrm{s})$ were conducted. For granite discontinuity 
samples 1\# to 3\#, firstly, the normal stress was applied in the load control mode until to the pre-set value with $100 \mathrm{kPa}$ or $200 \mathrm{kPa}$ with the loading rate of $2.5 \mathrm{kPa} / \mathrm{s}$, and then it remained constant. After that, the shear load was applied in the displacement control mode with a constant shear rate of $0.05 \mathrm{~mm} / \mathrm{s}$ until to the displacement value with $9 \mathrm{~mm}$, which was set in the test platform before the test. After the shear test, the next shear test was conducted on the identical sample under the same loading condition as mentioned above except that the shear rate was $0.1 \mathrm{~mm} / \mathrm{s}$. Then, the shear tests were conducted successively with the constant shear rate ranging from $0.2 \mathrm{~mm} / \mathrm{s}$ to $1 \mathrm{~mm} / \mathrm{s}$ once again. For the sample $4 \#$, according to the above loading procedures, the normal stress was $200 \mathrm{kPa}$; the shear rates were $0.1 \mathrm{~mm} / \mathrm{s}$, $0.5 \mathrm{~mm} / \mathrm{s}$ and $1 \mathrm{~mm} / \mathrm{s}$; the pre-set displacement value was $18 \mathrm{~mm}$. For the granite discontinuity sample $5 \#$, according to the above loading procedures, the normal stress was $100 \mathrm{kPa}$; the shear rate was ranging from $0.033 \mathrm{~mm} / \mathrm{s}$ to $0.25 \mathrm{~mm} / \mathrm{s}$; the pre-set displacement value was $30 \mathrm{~mm}$. During the direct shear tests, the shear load values were recorded in a real-time mode by the test platform.

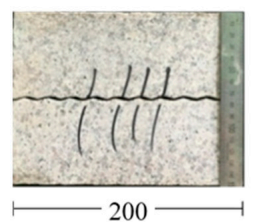

Sample 1 \#

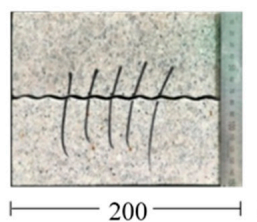

Sample 2 \#

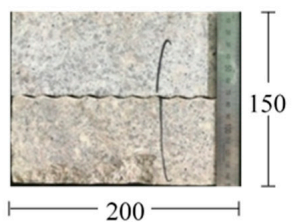

Sample 3 \#

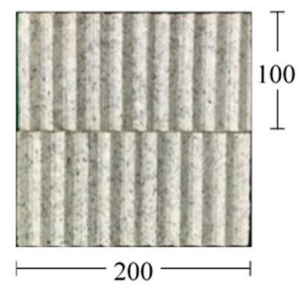

(a)

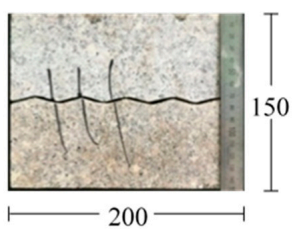

Sample 4 \#

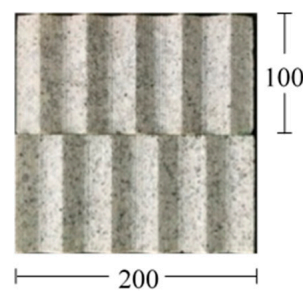

(b)

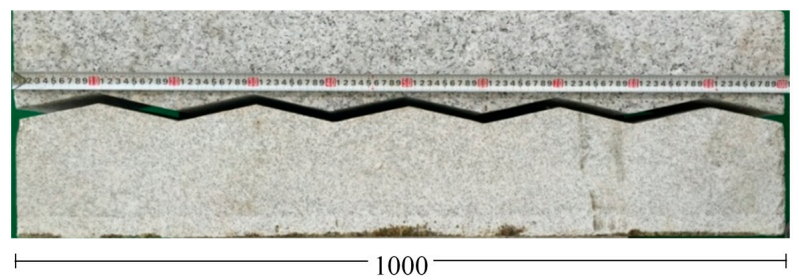

Sample 5 \#

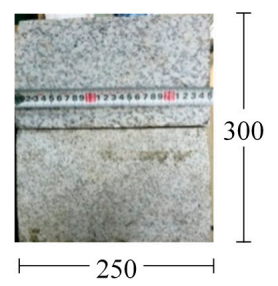

(c)

Figure 2. Schematic for granite discontinuity samples (unit: $\mathrm{mm}$ ) (a) The positive and top views of small samples numbered from $1 \#$ to $3 \# ;$; (b) The positive and top view of the small sample numbered 4\#; (c) The positive and side view of the large sample numbered $5 \#$.

Table 2. Geometric and strength parameters of different discontinuity samples.

\begin{tabular}{|c|c|c|c|c|c|c|}
\hline $\begin{array}{c}\text { Sample Type and } \\
\text { Number }\end{array}$ & $\begin{array}{c}\text { Sample Length, } \\
\text { Height, Width } \\
\text { (mm) }\end{array}$ & $\begin{array}{l}\text { Regular } \\
\text { Sawtooth } \\
\text { Number }\end{array}$ & $\begin{array}{l}\text { Sawtooth } \\
\text { Angle } \\
\left({ }^{\circ}\right)\end{array}$ & $\begin{array}{c}\text { Sawtooth } \\
\text { Length, Height } \\
(\mathrm{mm})\end{array}$ & $\begin{array}{l}\text { Average Value } \\
\text { of Uniaxial } \\
\text { Compressive } \\
\text { Strength } \\
\text { (MPa) }\end{array}$ & $\begin{array}{c}\text { Average Value of } \\
\text { Basic Friction Angle } \\
\left({ }^{\circ}\right)\end{array}$ \\
\hline Small sample & $200,150,100$ & 10 & 17 & $20,3.057$ & \multirow{3}{*}{200} & \multirow{3}{*}{25} \\
\hline $1 \#, 2 \#, 3 \#, 4 \#$ & $200,150,100$ & 5 & 16 & $40,5.735$ & & \\
\hline $\begin{array}{c}\text { Large sample } \\
\quad 5 \#\end{array}$ & $1000,300,250$ & 5 & 13 & $200,23.087$ & & \\
\hline
\end{tabular}




\subsection{Verification of the New Strength Equation}

To verify the feasibility of the new shear strength criterion, the experimental results were fitted by Equation (5) according to the method proposed by [54]. Let $V_{0}=1 \mathrm{~mm} / \mathrm{s}$, Equation (5) can be transformed into Equation (6):

$$
\arctan \left(\frac{\tau}{\sigma}\right)-J R C_{\mathrm{n}} \log _{10}\left(\frac{J C S_{\mathrm{n}}}{\sigma}\right)=M \log _{10}\left(\frac{1}{V}\right)+\varphi_{\mathrm{b}} .
$$

Note, that the left-hand side in Equation (6) can be regarded as the rate-dependent friction angle which was defined by [54].

We can obtain

$$
\varphi_{\mathrm{v}}=M \log _{10}(1 / V)+\varphi_{\mathrm{b}},
$$

where $\varphi_{\mathrm{v}}$ is the rate-dependent friction angle [54].

In the current study, the values of $\varphi_{\mathrm{v}}$ were first calculated by making use of the experimental results according to the left-hand side of Equation (6). Then, we directly used these values to fit Equation (7) by the least square method. In order to achieve the fitting process, the values of $J R C_{n}$ and $J C S_{\mathrm{n}}$ for granite discontinuity samples should be calculated initially.

As mentioned in Sections 2.1 and 2.2, during the calculation processes of $J R C_{n}$ and JCS $S_{n}$, the $\beta_{100 \%}$ in Equation (2) was taken as the value of the undulated angle of the granite discontinuity sample. Moreover, it is worth noting that Equation (2) was established on the basis of the Barton standard roughness profiles [35]. Hence, in Equation (5), $L_{0}$ and $h_{0}$ were assumed respectively to be $100 \mathrm{~mm}$ and the maximal undulated amplitude $(6.148 \mathrm{~mm})$ of all the Barton profiles [35]. Furthermore, $J C S_{0}$ was presumed to be the uniaxial compressive strength of granite [31,37].

According to the geometric and strength parameters for granite discontinuity samples in Table 2, the values of $J R C_{\mathrm{n}}$ and $J C S_{\mathrm{n}}$ for granite discontinuity samples were calculated respectively via Equations (2) to (4), as listed in Table 3.

Table 3. Values of $J R C_{\mathrm{n}}$ and $J C S_{\mathrm{n}}$ for different granite discontinuity samples.

\begin{tabular}{ccccc}
\hline Sample Type & $\begin{array}{c}\text { Undulated Angle } \\
\left({ }^{\circ}\right)\end{array}$ & $\begin{array}{c}\text { Sample Length } \\
(\mathbf{m m})\end{array}$ & $J R C_{\mathbf{n}}$ & $J C S_{\mathbf{n}}(\mathbf{M P a})$ \\
\hline Granite & 17 & 200 & 11.924 & 126.582 \\
discontinuity & 16 & 200 & 15.179 & 129.589 \\
& 13 & 1000 & 12.362 & 60.234 \\
\hline
\end{tabular}

\section{Results}

\subsection{Experimental Results}

After the shear tests, the peak shear strength of granite discontinuity samples under different shear conditions were illustrated in Table A1 and Figure 3. Figure 4 shows the surfaces of granite discontinuity samples after the tests.

As mentioned in Section 2.2, for the samples 1\#, 2\#, 3\# and 4\#, the discontinuity with the larger undulated amplitude has the higher $J R C_{n}$ value under the same discontinuity length condition (Table 3 ). Figure 3 shows that the peak shear strength of granite discontinuity samples increases with the shear rate's increase. For the samples 2\#, 3\# and 4\#, there is higher shear strength for the discontinuity with a larger undulated amplitude under the same normal stress condition. The shear rate effect of the sample $1 \#$ is more prominent than those of samples $2 \#$ and $3 \#$ under the condition that the normal stress is relatively larger. For each sample, the shear rate effect gradually fades away when the shear rate is larger than ca. $0.2 \mathrm{~mm} / \mathrm{s}$. As shown in Figure 4, it is noted that the upper and lower discontinuity surfaces represent respectively the overlying and underlying granite discontinuity samples $2 \#$ and $4 \#$. The red arrow indicates the direction of shear movement of the underlying discontinuity. The blue 
boxes in Figure $4 b$,d show the same parts as the red ones in Figure $4 a$,c. It can be clearly observed that the asperities of granite discontinuity samples 2\# and 4\# were worn. Because both the sample 2\# and 4\# were applied to a relatively small normal stress, asperities of granite discontinuity samples were grinded into tiny fragments. Nevertheless, it is difficult to observe an obvious change on the first-order irregularities after shear tests, but prone to recognize scratches on contact surfaces of the first-order irregularities, of which the direction is consistent with the shear direction. According to the above experimental results, we can verify the feasibility of both the new shear strength criterion and previous empirical equations listed in Table 1.

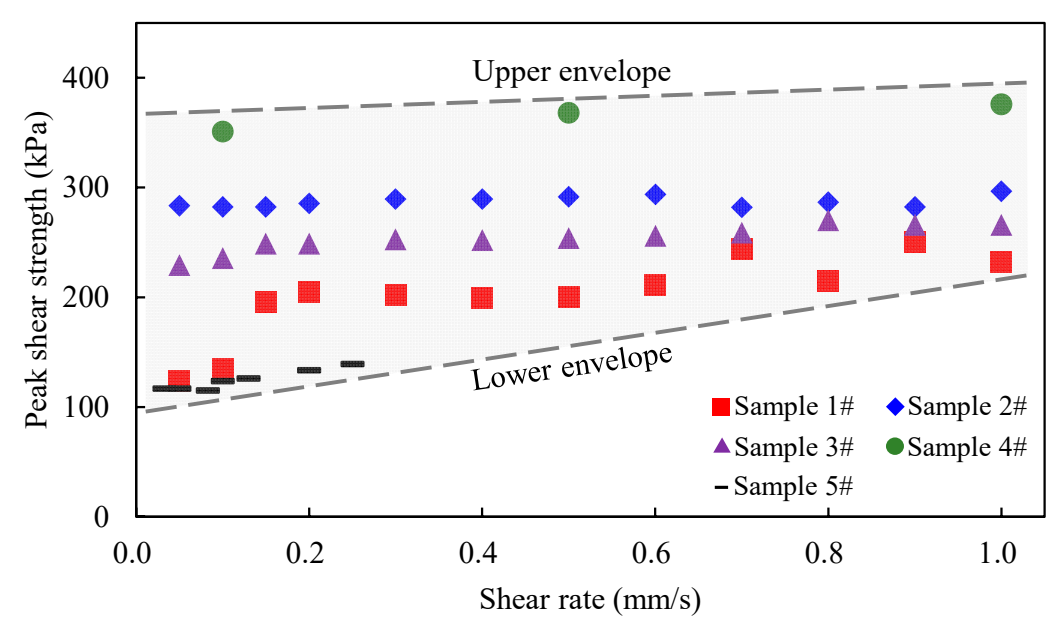

Figure 3. Peak shear strength of granite discontinuity samples under different normal stresses and shear rates.

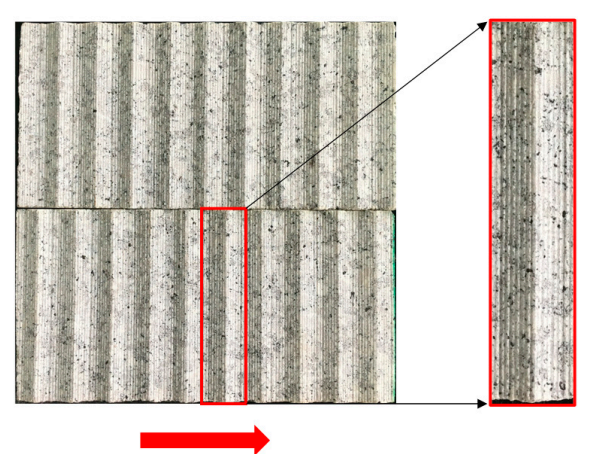

(a)

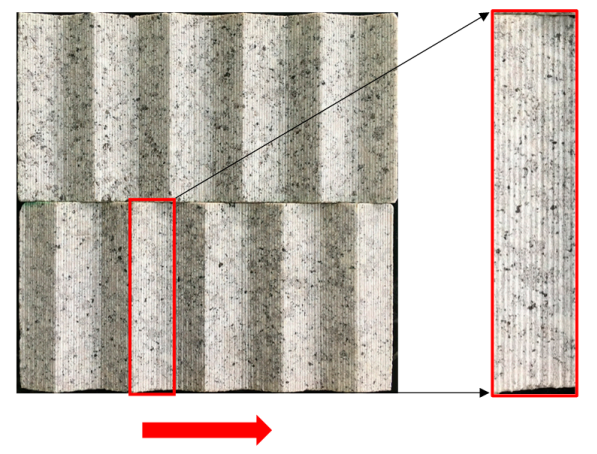

(c)

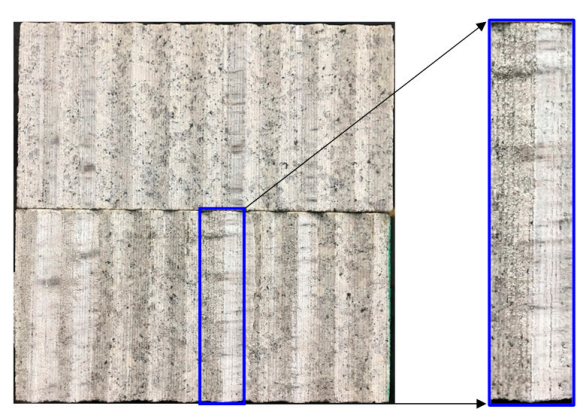

(b)

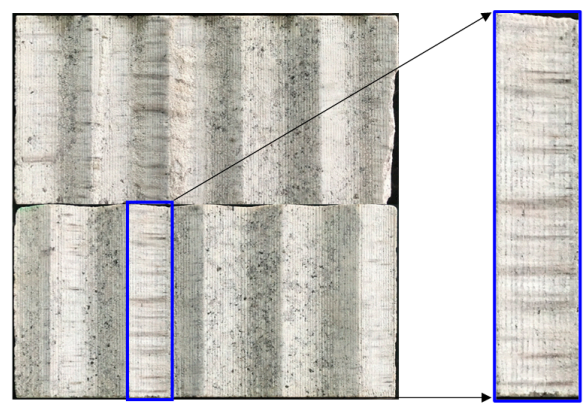

(d)

Figure 4. Morphology comparison for granite discontinuity samples 2\# and 4\# before and after tested (a) The top view of sample 2\# before tested; (b) The top view of sample 2\# after tested; (c) The top view of sample $4 \#$ before tested; (d) The top view of sample $4 \#$ after tested. 


\subsection{Comparison Experimental Data with Predicted Results}

\subsubsection{Rate-Dependent Friction Angle $\varphi_{\mathrm{V}}$}

In this section, we verified the feasibility of the new shear strength criterion. As mentioned in Section 2.3, the values of $\arctan (\tau / \sigma)$ and $J R C_{n} \cdot \log _{10}\left(J C S_{n} / \sigma\right)$ for the granite discontinuity samples were calculated based on Equation (6) and Table 3, as listed in Table A2. On the basis of Equations (6) and (7), values of the rate-dependent friction angle $\varphi_{\mathrm{v}}$ for granite discontinuity samples were calculated and the average values were listed in Table A3. According to Equation (7), the mathematical fitting between the rate-dependent friction angle $\varphi_{\mathrm{v}}$ for granite discontinuity samples and the shear rate $V$ was conducted. The relationship between $\log _{10}(1 / V)$ and the rate-dependent friction angle $\varphi_{\mathrm{V}}$ was shown in Figure 5.

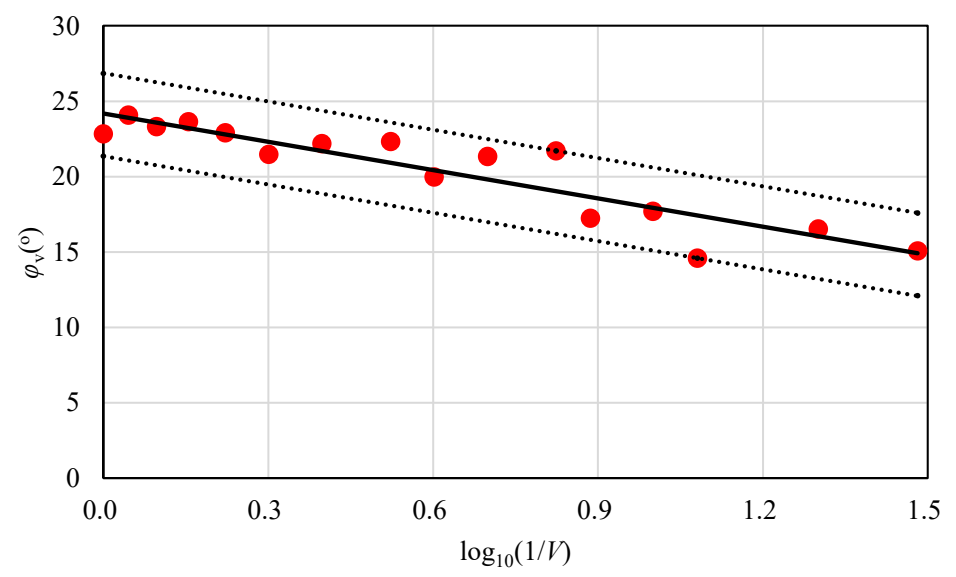

Figure 5. Relationship between average value of the rate-dependent friction angle $\varphi_{\mathrm{v}}$ and $\log _{10}(1 / V)$ of granite discontinuity samples.

The linear regression analysis was performed on the test data in Figure 5:

$$
\varphi_{\mathrm{v}}=-6.2538 \log _{10}(1 / V)+24.188,
$$

where the squared value of the correlation coefficient $R^{2}=0.834$.

According to Equation (8) and Figure 5, a strong linear relationship between the rate-dependent friction angle $\varphi_{\mathrm{v}}$ and $\log _{10}(1 / V)$ is presented, with a high value of $R^{2}(0.834)$. There is an absolute difference between theoretically predicted results and experimental data, wherein exists a ratio within $11.7 \%$ in comparison with the theoretically predicted results. Moreover, the intercept value of the fitting Equation (8) is $24.188^{\circ}$. It is very close to the average value of the basic friction angle $\left(25^{\circ}\right)$ for granite discontinuity samples. Therefore, the relationship between the rate-dependent friction angle $\varphi_{\mathrm{v}}$ of granite discontinuity samples and $\log _{10}(1 / \mathrm{V})$ can be fitted by Equation (7) in a good manner.

To check the generality of the new equation, we introduced the indoor direct shear test data of cement discontinuities under the different shear rates and constant normal load condition [51]. The geometric and strength parameters, such as the sample morphology, length, maximal undulated amplitude, uniaxial compressive strength and basic friction angle of cement discontinuities with regular sawtooth shapes were listed in Table 4. By utilizing Equations (2) to (4), the values of $J R C_{n}$ and $J C S_{\mathrm{n}}$ for cement discontinuity samples were calculated respectively, as listed in Table 4.

Based on Equation (6) and Table 4, the values of $\arctan (\tau / \sigma)$ and $J R C_{n} \cdot \log _{10}\left(J C S_{n} / \sigma\right)$ for cement discontinuity samples were calculated, as listed in Table A4 (after [51]). On the basis of Equations (6) and (7), values of the rate-dependent friction angle $\varphi_{\mathrm{v}}$ for cement discontinuity samples were calculated and the average values were listed in Table A5. According to Equation (7), the mathematical fitting between the rate-dependent friction angle $\varphi_{\mathrm{v}}$ for cement discontinuity samples and the shear rate $V$ was performed. Figure 6 shows the relationship between $\log _{10}(1 / V)$ and rate-dependent friction angle $\varphi_{\mathrm{v}}$. 
Table 4. Geometric and strength parameters of different cement discontinuity samples (after [51]).

\begin{tabular}{|c|c|c|c|c|c|c|c|}
\hline Sample Type & $\begin{array}{l}\text { Undulated } \\
\text { Angle }\left({ }^{\circ}\right)\end{array}$ & $L_{\mathrm{n}}(\mathrm{mm})$ & $h_{\mathrm{n}}(\mathrm{mm})$ & $\begin{array}{l}J C S_{0} \\
(\mathrm{MPa})\end{array}$ & $\varphi_{\mathrm{b}}\left({ }^{\circ}\right)$ & $J R C_{\mathrm{n}}$ & $\begin{array}{l}J C S_{\mathrm{n}} \\
\text { (MPa) }\end{array}$ \\
\hline \multirow{3}{*}{$\begin{array}{l}\text { Cement discontinuities with } \\
\text { regular sawtooth shape }\end{array}$} & 15 & \multirow{3}{*}{150} & 4.019 & \multirow{3}{*}{22.5} & \multirow{3}{*}{36.22} & 14.213 & \multirow{3}{*}{17.701} \\
\hline & 30 & & 4.33 & & & 20.762 & \\
\hline & 45 & & 7.5 & & & 40.309 & \\
\hline
\end{tabular}

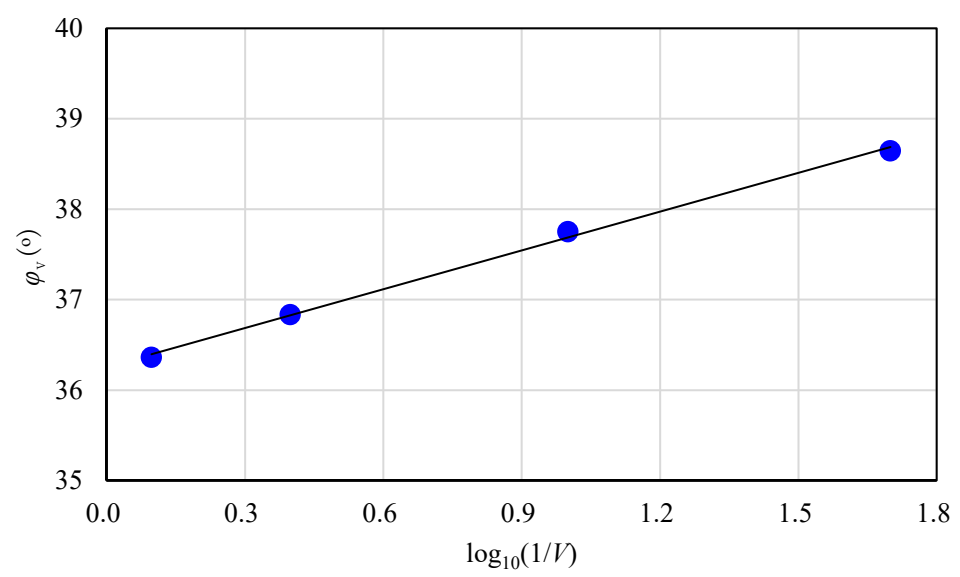

Figure 6. Relationship between average value of the rate-dependent friction angle $\varphi_{\mathrm{v}}$ and $\log _{10}(1 / V)$ of cement discontinuity samples.

According to Figure 6, there is a solid linear relationship between the rate-dependent friction angle $\varphi_{\mathrm{v}}$ and $\log _{10}(1 / V)$ :

$$
\varphi_{\mathrm{v}}=1.4288 \log _{10}(1 / V)+36.259,
$$

where the squared value of the correlation coefficient $R^{2}=0.9976$.

The intercept value of Equation (9) is $36.259^{\circ}$, which is very close to the average value of the basic friction angle $\left(36.22^{\circ}\right)$ for cement discontinuity samples [51]. Furthermore, the value of $R^{2}$ can reach 0.9976. Hence, the relationship between the rate-dependent friction angle $\varphi_{\mathrm{v}}$ of cement discontinuities and $\log _{10}(1 / V)$ can be fitted by Equation (7) well.

Based on the analysis above, it is proved that the hypothetical new shear strength criterion (Equation (5)) is feasible.

\subsubsection{Peak Shear Strength}

In this section, we predicted the peak shear strength of granite discontinuity samples by the new criterion and previous empirical equations (Table 1). Then, they were compared with experimental results to explore the applicability of previous empirical equations (Table 1). According to Section 2, the new shear strength criterion can be uniformly written as:

$$
\tau=\sigma \tan \left\{\log _{10}\left[\left(\left(\frac{J C S_{0}}{\sigma}\right)\left(\frac{L_{\mathrm{n}}}{L_{0}}\right)^{-0.03 J R C_{0}}\right)^{J R C_{0}\left(\frac{L_{\mathrm{n}}}{16.27 h_{\mathrm{n}}}\right)^{-0.02 J R C_{0}}} \cdot\left(\frac{V_{0}}{V}\right)^{M}\right]+\varphi_{\mathrm{b}}\right\}
$$

where $L_{0}$ is the discontinuity characteristic length, which is taken as $100 \mathrm{~mm}$ in the current study; $V_{0}$ is the characteristic rate, which is taken as $1 \mathrm{~mm} / \mathrm{s}$ in this study.

Considering the uncertainty coefficients in Equations (d) and (e), Equations (a) to (c) as well as the Barton shear strength empirical equation $[21,37,40]$ were adopted to calculate the theoretically predicted results. On the basis of the Tables 2 and 3 and Equations (a), (b), (c), (8) and (10), a series of theoretically predicted results of peak shear strength for granite discontinuity samples were calculated, 
as shown in Figure 7. The error values of theoretically predicted results by the new shear strength criterion were also acquired (Table A6).

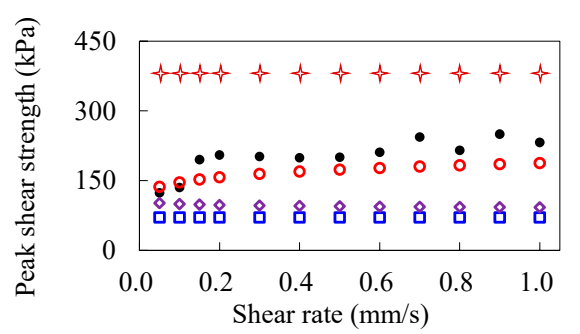

(a)

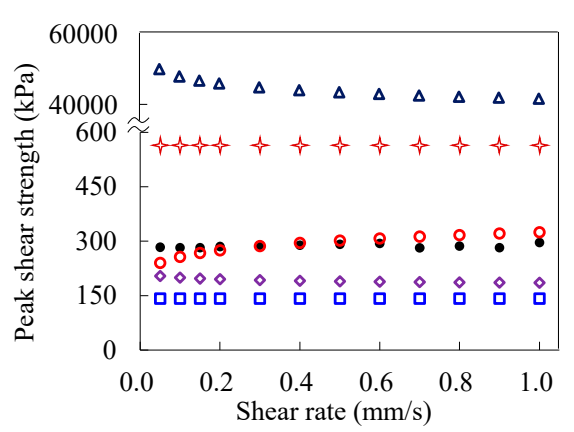

(b)

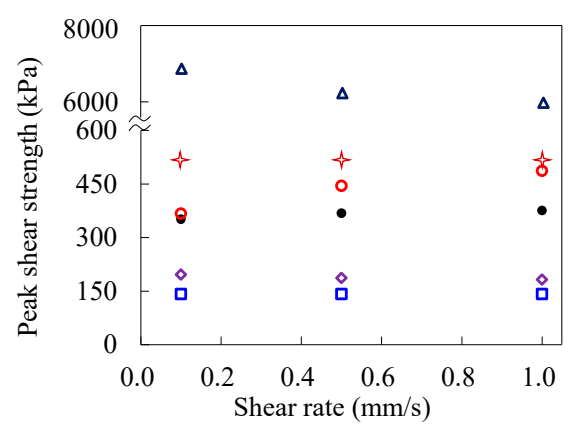

(d)

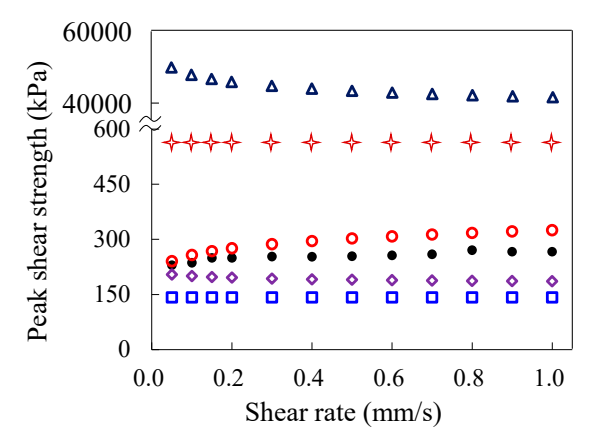

(c)

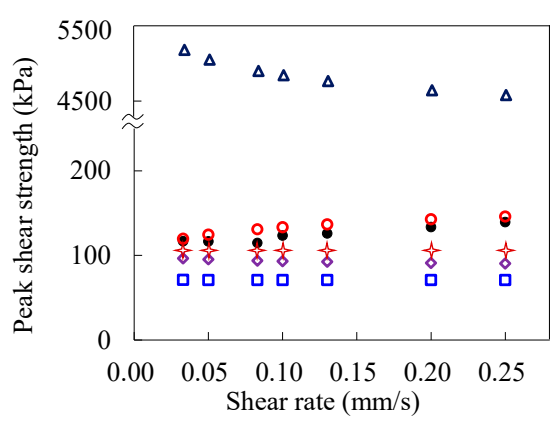

(e)

$$
\begin{aligned}
& \text { Legend: - Experimental data } \bigcirc \text { New equation predicted results } \leftrightarrow \text { Barton equation predicted results } \\
& \square \text { Equation (1) predicted results } \diamond \text { Equation (2) predicted results } \Delta \text { Equation (3) predicted results }
\end{aligned}
$$

Figure 7. Comparison on the peak shear strength between the experimental data and the predicted results for granite discontinuity samples (a) Case of sample 1\#; (b) Case of sample 2\#; (c) Case of sample 3\#; (d) Case of sample 4\#; (e) Case of sample 5\#. Note that in case of sample 1\#, the predicted results calculated via Equation (c) are negative which were not drawn.

\section{Discussion}

As shown in Figure 7, it can be seen that the theoretically predicted results calculated by the Barton shear strength empirical equation keep invariant with the shear rate increasing. For small samples (1\# to $4 \#$ ), the theoretically predicted shear strength results overestimate the experimental results while they underestimate the test data for the large sample (5\#). It has no capability of prediction on the rate-dependent increasing tendency of granite discontinuity samples. It also displays that previous empirical Equations (a) to (c) cannot predict the peak shear strength of granite discontinuity samples accurately. For one thing, the theoretically predicted results calculated via previous empirical equations are obliviously different from the experimental results. For another, the variation trends 
of the theoretically predicted results are opposite to those of the experimental results. In detail, the theoretically predicted shear strength results calculated by Equation (a) are almost invariable and basically independent on the shear rate; while the theoretically predicted results calculated via Equations (b) and (c) decrease with the shear rate increasing. Nevertheless, the results predicted by the new shear strength criterion agree well with the experimental results in terms of both the value and the variation tendency.

As mentioned above, it indicates that Equations (a) to (c) are not applicable from two aspects, i.e., the value and the variation trend to predict the shear strength of granite discontinuity samples taking into account the shear rate. The reason for this may be attributed to the difference of the material property. It is reported in Section 1 that there exists two types of rock materials. One has the shear rate-strengthening effect for the shear strength of the rock discontinuities such as concrete, the other has the shear rate-weakening effect for the shear strength of the rock discontinuities such as cement $[49,52,54]$. Equations (b) and (c) were established respectively based on the shear tests of cement and cement mortar discontinuities [51,53]. Thus, the theoretically predicted results from Equations (b) and (c) are not applicable to predict the experimental results of granite discontinuity samples, which increase with the shear rate increasing. Compared with previous equations (Equations (a) to (c)), the new shear strength criterion is applicable to predict the shear strength of both the rock discontinuities with the shear rate-strengthening effect such as granite and discontinuities with the shear rate-weakening effect such as cement under various shear rates, by setting different values of coefficient $M$.

According to Equation (9), the intercept value is much closer to the basic friction angle than that $\left(36.432^{\circ}\right)$ obtained by [54], which indicates that the new shear strength criterion has a better prediction accuracy than the previous equation, such as Equation (d) proposed by [54]. This equation did not take both the discontinuity length and the undulated amplitude into account simultaneously. According to Figure 7, the error values indicate that the larger the scale of the rock discontinuities, the higher the accuracy of the new shear strength criterion. In practical applications, the length of the rock discontinuity ranges from meters to kilometers. Hence, the new shear strength criterion is applicable and feasible for the evaluation of the stability of the rock mass.

By normalization, the factors of the discontinuity size and the shear rate are incorporated into the total friction angle [21,37], thus the dimension unity of the new shear strength criterion can be fulfilled with definite physical meaning. Therefore, the new shear strength criterion can take into account the normal stress, undulated angle and basic friction angle, discontinuity length, undulated amplitude and the shear rate simultaneously comparing with previous equations (Table 1). Additionally, the new shear strength criterion can be degraded into ISRM-suggested Barton shear strength empirical equation on condition that the shear rate is equal to the characteristic rate and the undulated amplitude equates the maximal undulated amplitude of all the Barton profiles.

The characteristic rate in the new shear strength criterion (i.e., Equation (10)) may vary with different lithology. As well as the characteristic rate, the coefficient $M$ in the new shear strength criterion can be obtained by numerous direct shear tests on the discontinuities with various physical properties and microgeometric morphology. In further study, a large number of dynamic direct shear tests should be conducted on the natural discontinuities and artificial discontinuities of different lithology, and material properties considering more scales, larger normal stresses and shear rates by making full use of the new dynamic direct shear testing device on rock joints.

\section{Conclusions}

In this paper, we established a new criterion on the peak shear strength of the rock discontinuities taking into account both the size effects induced by the discontinuity length as well as the undulated amplitude and the shear rate effect simultaneously. Then, a series of direct shear tests on granite discontinuities with various sizes (i.e., lengths from $200 \mathrm{~mm}$ to $1000 \mathrm{~mm}$ and undulated amplitudes from $3 \mathrm{~mm}$ to $23 \mathrm{~mm}$ ) and regular sawtooth shapes under different low shear rates $(0 \mathrm{~mm} / \mathrm{s}$ to $1 \mathrm{~mm} / \mathrm{s})$ were conducted on the basis of a new dynamic direct shear testing device on rock joints. It was proved that 
the new shear strength criterion could accurately predict the experimental results. The absolute value for the ratio of error value to experimental result was mostly within 0.2 , while previous empirical equations lose this capability. The new shear strength criterion has the advantage of dimension unity. Additionally, it can be degraded into the Barton shear strength empirical equation on the peak shear strength of the rock discontinuities, which is more general and applicable in the stability evaluation of the rock mass.

Author Contributions: Conceptualization, S.Q. and B.Z.; methodology, B.Z. and S.Q.; software, B.Z.; validation, X.H. and S.G.; formal analysis, B.Z., S.Q., X.H. and S.G.; investigation, C.W., Z.Z. and G.L.; resources, B.Z. and S.Q.; data curation, B.Z., S.Q., X.H. and S.G.; writing-original draft preparation, B.Z.; writing-review and editing, S.Q., X.H. and S.G.; visualization, C.W., Z.Z. and G.L.; supervision, B.Z. and S.Q.; project administration, S.Q.; funding acquisition, S.Q., B.Z., S.G. and X.H. All authors have read and agreed to the published version of the manuscript.

Funding: This research was supported by funds of National Natural Science Foundation of China under grants Nos. 41825018, 41672307, 41902289, 41702345, 41807273 and China Postdoctoral Science Foundation under grant No. 2017M620903.

Conflicts of Interest: The authors declare no conflict of interest.

\section{Appendix A}

Table A1. Peak shear strength of granite discontinuity samples under different normal stresses and shear rates.

\begin{tabular}{|c|c|c|c|}
\hline Sample Number & Normal Stress (kPa) & Shear Rate $(\mathrm{mm} / \mathrm{s})$ & Peak Shear Strength $(\mathrm{kPa})$ \\
\hline \multirow{12}{*}{ Sample 1\# } & \multirow{12}{*}{100} & 0.05 & 123.85 \\
\hline & & 0.1 & 135.4 \\
\hline & & 0.15 & 195.7 \\
\hline & & 0.2 & 205.55 \\
\hline & & 0.3 & 202.25 \\
\hline & & 0.4 & 199.5 \\
\hline & & 0.5 & 200.6 \\
\hline & & 0.6 & 211.6 \\
\hline & & 0.7 & 243.9 \\
\hline & & 0.8 & 215.4 \\
\hline & & 0.9 & 250.5 \\
\hline & & 1.0 & 232.4 \\
\hline \multirow{12}{*}{ Sample 2\# } & \multirow{12}{*}{200} & 0.05 & 283.7 \\
\hline & & 0.1 & 282.6 \\
\hline & & 0.15 & 282.6 \\
\hline & & 0.2 & 285.9 \\
\hline & & 0.3 & 289.75 \\
\hline & & 0.4 & 289.75 \\
\hline & & 0.5 & 291.9 \\
\hline & & 0.6 & 294.1 \\
\hline & & 0.7 & 282.05 \\
\hline & & 0.8 & 286.95 \\
\hline & & 0.9 & 282.6 \\
\hline & & 1.0 & 296.85 \\
\hline \multirow{12}{*}{ Sample 3\# } & \multirow{12}{*}{200} & 0.05 & 229.5 \\
\hline & & 0.1 & 236.05 \\
\hline & & 0.15 & 249.2 \\
\hline & & 0.2 & 249.2 \\
\hline & & 0.3 & 253.05 \\
\hline & & 0.4 & 252.5 \\
\hline & & 0.5 & 254.15 \\
\hline & & 0.6 & 256.35 \\
\hline & & 0.7 & 259.05 \\
\hline & & 0.8 & 270.55 \\
\hline & & 0.9 & 266.2 \\
\hline & & 1.0 & 266.2 \\
\hline
\end{tabular}


Table A1. Cont.

\begin{tabular}{cccc}
\hline Sample Number & Normal Stress $\mathbf{( k P a )}$ & Shear Rate $\mathbf{( m m} / \mathbf{s})$ & Peak Shear Strength $\mathbf{( k P a )}$ \\
\hline \multirow{3}{*}{ Sample 4\# } & \multirow{2}{*}{200} & 0.1 & 351.35 \\
& & 0.5 & 368.35 \\
& 1.0 & 376.05 \\
\hline & & 0.033 & 116.788 \\
Sample 5\# & \multirow{3}{*}{100} & 0.05 & 116.664 \\
& & 0.083 & 114.876 \\
& & 0.1 & 123.496 \\
& & 0.2 & 126.148 \\
& & 0.25 & 133.58 \\
& &
\end{tabular}

Table A2. Test data of different granite discontinuity samples with the shear rate varying from $0.03 \mathrm{~mm} / \mathrm{s}$ to $1 \mathrm{~mm} / \mathrm{s}$.

\begin{tabular}{|c|c|c|c|c|c|}
\hline Sample Type & $\begin{array}{c}\text { Shear Rate } \\
V(\mathrm{~mm} / \mathrm{s})\end{array}$ & $\begin{array}{c}\text { Peak Shear } \\
\text { Strength } \\
\tau(\mathrm{MPa})\end{array}$ & $\begin{array}{c}\text { Normal Stress } \\
\sigma(\mathrm{MPa})\end{array}$ & $\begin{array}{c}\operatorname{Arctan}(\tau / \sigma) \\
\left({ }^{\circ}\right)\end{array}$ & $\begin{array}{c}J R C_{\mathrm{n}} \cdot \log _{10} \\
\left(J C S_{\mathrm{n}} / \sigma\right) \\
\left({ }^{\circ}\right)\end{array}$ \\
\hline \multirow{36}{*}{$\begin{array}{c}\text { Granite } \\
\text { discontinuity } \\
\left(17^{\circ}\right)\end{array}$} & 0.05 & 0.124 & 0.1 & 51.082 & 36.994 \\
\hline & 0.05 & 0.284 & 0.2 & 54.817 & 33.404 \\
\hline & 0.05 & 0.230 & 0.2 & 48.929 & 33.404 \\
\hline & 0.1 & 0.135 & 0.1 & 53.552 & 36.994 \\
\hline & 0.1 & 0.283 & 0.2 & 54.712 & 33.404 \\
\hline & 0.1 & 0.236 & 0.2 & 49.726 & 33.404 \\
\hline & 0.15 & 0.196 & 0.1 & 62.934 & 36.994 \\
\hline & 0.15 & 0.283 & 0.2 & 54.712 & 33.404 \\
\hline & 0.15 & 0.249 & 0.2 & 51.251 & 33.404 \\
\hline & 0.2 & 0.206 & 0.1 & 64.057 & 36.994 \\
\hline & 0.2 & 0.286 & 0.2 & 55.025 & 33.404 \\
\hline & 0.2 & 0.249 & 0.2 & 51.251 & 33.404 \\
\hline & 0.3 & 0.202 & 0.1 & 63.690 & 36.994 \\
\hline & 0.3 & 0.290 & 0.2 & 55.385 & 33.404 \\
\hline & 0.3 & 0.253 & 0.2 & 51.679 & 33.404 \\
\hline & 0.4 & 0.200 & 0.1 & 63.378 & 36.994 \\
\hline & 0.4 & 0.290 & 0.2 & 55.385 & 33.404 \\
\hline & 0.4 & 0.253 & 0.2 & 51.618 & 33.404 \\
\hline & 0.5 & 0.201 & 0.1 & 63.504 & 36.994 \\
\hline & 0.5 & 0.292 & 0.2 & 55.582 & 33.404 \\
\hline & 0.5 & 0.254 & 0.2 & 51.799 & 33.404 \\
\hline & 0.6 & 0.212 & 0.1 & 64.705 & 36.994 \\
\hline & 0.6 & 0.294 & 0.2 & 55.783 & 33.404 \\
\hline & 0.6 & 0.256 & 0.2 & 52.039 & 33.404 \\
\hline & 0.7 & 0.244 & 0.1 & 67.706 & 36.994 \\
\hline & 0.7 & 0.282 & 0.2 & 54.660 & 33.404 \\
\hline & 0.7 & 0.259 & 0.2 & 52.330 & 33.404 \\
\hline & 0.8 & 0.215 & 0.1 & 65.097 & 36.994 \\
\hline & 0.8 & 0.287 & 0.2 & 55.124 & 33.404 \\
\hline & 0.8 & 0.271 & 0.2 & 53.527 & 33.404 \\
\hline & 0.9 & 0.251 & 0.1 & 68.238 & 36.994 \\
\hline & 0.9 & 0.283 & 0.2 & 54.712 & 33.404 \\
\hline & 0.9 & 0.266 & 0.2 & 53.082 & 33.404 \\
\hline & 1 & 0.232 & 0.1 & 66.718 & 36.994 \\
\hline & 1 & 0.297 & 0.2 & 56.030 & 33.404 \\
\hline & 1 & 0.266 & 0.2 & 53.082 & 33.404 \\
\hline Granite & 0.1 & 0.351 & 0.2 & 60.350 & 42.677 \\
\hline discontinuity & 0.5 & 0.368 & 0.2 & 61.500 & 42.677 \\
\hline$\left(16^{\circ}\right)$ & 1 & 0.376 & 0.2 & 61.994 & 42.677 \\
\hline
\end{tabular}


Table A2. Cont.

\begin{tabular}{cccccc}
\hline Sample Type & $\begin{array}{c}\text { Shear Rate } \\
\boldsymbol{V}(\mathbf{m m} / \mathbf{s})\end{array}$ & $\begin{array}{c}\text { Peak Shear } \\
\text { Strength } \\
\tau(\mathbf{M P a})\end{array}$ & $\begin{array}{c}\text { Normal Stress } \\
\boldsymbol{\sigma}(\mathbf{M P a})\end{array}$ & $\begin{array}{c}\text { Arctan }(\tau / \sigma) \\
\left.\mathbf{(}^{\circ}\right)\end{array}$ & $\begin{array}{c}J R C_{\mathbf{n}} \cdot \log _{10} \\
\left(J C S_{\mathbf{n}} / \sigma\right) \\
\left({ }^{\circ}\right)\end{array}$ \\
\hline & 0.033 & 0.117 & 0.1 & 49.428 & 34.363 \\
Granite & 0.05 & 0.117 & 0.1 & 49.398 & 34.363 \\
discontinuity & 0.083 & 0.115 & 0.1 & 48.960 & 34.363 \\
$\left(13^{\circ}\right)$ & 0.1 & 0.123 & 0.1 & 51.001 & 34.363 \\
& 0.13 & 0.126 & 0.1 & 51.595 & 34.363 \\
& 0.2 & 0.134 & 0.1 & 53.181 & 34.363 \\
& 0.25 & 0.139 & 0.1 & 54.339 & 34.363 \\
\hline
\end{tabular}

Table A3. Average values of rate-dependent friction angle $\varphi_{\mathrm{v}}$ for different granite discontinuity samples with the shear rate varying from $0.03 \mathrm{~mm} / \mathrm{s}$ to $1 \mathrm{~mm} / \mathrm{s}$.

\begin{tabular}{ccc}
\hline Sample Type & $\begin{array}{c}\text { Shear Rate } \\
\boldsymbol{V}(\mathbf{m m} / \mathbf{s})\end{array}$ & Average Value $\left.\boldsymbol{\varphi}_{\mathbf{v}} \mathbf{(}^{\circ}\right)$ \\
\hline 0.033 & 15.065 \\
0.05 & 16.515 \\
0.083 & 14.597 \\
0.1 & 17.700 \\
0.13 & 17.232 \\
0.15 & 21.698 \\
0.2 & 21.337 \\
Granite discontinuity & 0.25 & 19.976 \\
& 0.3 & 22.317 \\
0.4 & 22.193 \\
& 0.5 & 21.477 \\
0.6 & 22.908 \\
0.7 & 23.631 \\
& 0.8 & 23.315 \\
& 0.9 & 24.077 \\
\end{tabular}

Table A4. Test data of different cement discontinuity samples with the shear rate varying from $0.02 \mathrm{~mm} / \mathrm{s}$ to $1 \mathrm{~mm} / \mathrm{s}$ (after [51]).

\begin{tabular}{cccccc}
\hline Sample Type & $\begin{array}{c}\text { Shear Rate } \\
\boldsymbol{V}(\mathbf{m m} / \mathbf{s})\end{array}$ & $\begin{array}{c}\text { Peak Shear } \\
\text { Strength } \\
\boldsymbol{\tau} \mathbf{( M P a )}\end{array}$ & $\begin{array}{c}\text { Normal Stress } \\
\boldsymbol{\sigma} \mathbf{( M P a )}\end{array}$ & $\begin{array}{c}\text { Arctan }(\tau / \sigma) \\
\left({ }^{\circ}\right)\end{array}$ & $\begin{array}{c}J R C_{\mathbf{n}} \cdot \log _{10} \\
\left(J C S_{\mathbf{n}} / \sigma\right) \\
\left({ }^{\circ}\right)\end{array}$ \\
\hline & 0.02 & 1.695 & 1 & 14.213 & 17.737 \\
& 0.02 & 2.39 & 1 & 20.762 & 25.911 \\
& 0.02 & 2.71 & 1 & 40.309 & 50.306 \\
& 0.02 & 3.11 & 2 & 14.213 & 13.459 \\
Cement & 0.02 & 4.208 & 2 & 20.762 & 19.661 \\
& 0.02 & 4.58 & 2 & 40.309 & 38.171 \\
& 0.02 & 4.45 & 3 & 14.213 & 10.956 \\
& 0.02 & 6.289 & 3 & 20.762 & 16.005 \\
& 0.02 & 6.69 & 3 & 40.309 & 31.073 \\
& 0.1 & 1.675 & 1 & 14.213 & 17.737 \\
& 0.1 & 2.33 & 1 & 20.762 & 25.911 \\
& 0.1 & 2.63 & 1 & 40.309 & 50.306 \\
& 0.1 & 3.02 & 2 & 14.213 & 13.459 \\
& 0.1 & 4.02 & 2 & 20.762 & 19.661 \\
& 0.1 & 4.31 & 2 & 40.309 & 38.171 \\
& 0.1 & 4.3 & 3 & 14.213 & 10.956 \\
& 0.1 & 5.96 & 3 & 20.762 & 16.005 \\
& 0.1 & 6.27 & 3 & 40.309 & 31.073 \\
\hline
\end{tabular}


Table A4. Cont.

\begin{tabular}{|c|c|c|c|c|c|}
\hline Sample Type & $\begin{array}{c}\text { Shear Rate } \\
V(\mathrm{~mm} / \mathrm{s})\end{array}$ & $\begin{array}{c}\text { Peak Shear } \\
\text { Strength } \\
\tau(\mathrm{MPa})\end{array}$ & $\begin{array}{c}\text { Normal Stress } \\
\sigma(\mathrm{MPa})\end{array}$ & $\underset{\left({ }^{\circ}\right)}{\operatorname{Arctan}}(\tau / \sigma)$ & $\begin{array}{c}J R C_{\mathrm{n}} \cdot \log _{10} \\
\left(J C S_{\mathrm{n}} / \sigma\right) \\
\left(^{\circ}\right)\end{array}$ \\
\hline \multirow{18}{*}{$\begin{array}{c}\text { Cement } \\
\text { discontinuity }\end{array}$} & 0.4 & 1.64 & 1 & 14.213 & 17.737 \\
\hline & 0.4 & 2.29 & 1 & 20.762 & 25.911 \\
\hline & 0.4 & 2.57 & 1 & 40.309 & 50.306 \\
\hline & 0.4 & 2.83 & 2 & 14.213 & 13.459 \\
\hline & 0.4 & 3.81 & 2 & 20.762 & 19.661 \\
\hline & 0.4 & 4.14 & 2 & 40.309 & 38.171 \\
\hline & 0.4 & 4.09 & 3 & 14.213 & 10.956 \\
\hline & 0.4 & 5.79 & 3 & 20.762 & 16.005 \\
\hline & 0.4 & 5.99 & 3 & 40.309 & 31.073 \\
\hline & 0.8 & 1.63 & 1 & 14.213 & 17.737 \\
\hline & 0.8 & 2.28 & 1 & 20.762 & 25.911 \\
\hline & 0.8 & 2.55 & 1 & 40.309 & 50.306 \\
\hline & 0.8 & 2.75 & 2 & 14.213 & 13.459 \\
\hline & 0.8 & 3.75 & 2 & 20.762 & 19.661 \\
\hline & 0.8 & 4.03 & 2 & 40.309 & 38.171 \\
\hline & 0.8 & 3.95 & 3 & 14.213 & 10.956 \\
\hline & 0.8 & 5.61 & 3 & 20.762 & 16.005 \\
\hline & 0.8 & 5.89 & 3 & 40.309 & 31.073 \\
\hline
\end{tabular}

Table A5. Average values of rate-dependent friction angle $\varphi_{\mathrm{v}}$ for different cement discontinuity samples with the shear rate varying from $0.02 \mathrm{~mm} / \mathrm{s}$ to $1 \mathrm{~mm} / \mathrm{s}$.

\begin{tabular}{ccc}
\hline Sample Type & $\begin{array}{c}\text { Shear Rate } \\
\boldsymbol{V}(\mathbf{m m} / \mathbf{s})\end{array}$ & Average Value $\varphi_{\mathbf{v}}\left(^{\circ}\right)$ \\
\hline \multirow{3}{*}{ Cement discontinuity } & 0.02 & 38.647 \\
& 0.1 & 37.754 \\
& 0.4 & 36.835 \\
& 0.8 & 36.362 \\
\hline
\end{tabular}

Table A6. Theoretically predicted results of peak shear strength for granite discontinuity samples calculated via the new empirical equation and the corresponding error values.

\begin{tabular}{ccccccc}
\hline $\begin{array}{c}\text { Sample } \\
\text { Number }\end{array}$ & $\begin{array}{c}\text { Normal } \\
\text { Stress } \\
(\mathbf{k P a})\end{array}$ & $\begin{array}{c}\text { Shear } \\
\text { Rate } \\
(\mathbf{m m} / \mathbf{s})\end{array}$ & $\begin{array}{c}\text { Experimental } \\
\text { Result } \\
\mathbf{( k P a )}\end{array}$ & $\begin{array}{c}\text { Predicted } \\
\text { Result } \\
\mathbf{( k P a )}\end{array}$ & $\begin{array}{c}\text { Error } \\
\text { Value } \\
\mathbf{( k P a )}\end{array}$ & $\begin{array}{c}\text { Ratio of Error } \\
\text { Value to } \\
\text { Experimental } \\
\text { Result (\%) }\end{array}$ \\
\hline & & 0.05 & 123.85 & 136.91 & 13.06 & 10.55 \\
& & 0.1 & 135.4 & 146.81 & 11.41 & 8.43 \\
& & 0.15 & 195.7 & 153.05 & -42.65 & -21.79 \\
& & 0.2 & 205.55 & 157.71 & -47.84 & -23.28 \\
& & 0.3 & 202.25 & 164.62 & -37.63 & -18.61 \\
& \multirow{2}{*}{100} & 0.4 & 199.5 & 169.79 & -29.71 & -14.89 \\
& & 0.5 & 200.6 & 173.98 & -26.62 & -13.27 \\
& & 0.6 & 211.6 & 177.51 & -34.09 & -16.11 \\
& & 0.7 & 243.9 & 180.58 & -63.32 & -25.96 \\
& & 0.8 & 215.4 & 183.31 & -32.09 & -14.90 \\
& & 0.9 & 250.5 & 185.77 & -64.73 & -25.84 \\
& & 232.4 & 188.01 & -44.39 & -19.10 \\
\hline
\end{tabular}


Table A6. Cont.

\begin{tabular}{|c|c|c|c|c|c|c|}
\hline $\begin{array}{l}\text { Sample } \\
\text { Number }\end{array}$ & $\begin{array}{c}\text { Normal } \\
\text { Stress } \\
\text { (kPa) }\end{array}$ & $\begin{array}{c}\text { Shear } \\
\text { Rate } \\
(\mathrm{mm} / \mathrm{s})\end{array}$ & $\begin{array}{c}\text { Experimental } \\
\text { Result } \\
(\mathbf{k P a})\end{array}$ & $\begin{array}{c}\text { Predicted } \\
\text { Result } \\
(\mathbf{k P a})\end{array}$ & $\begin{array}{l}\text { Error } \\
\text { Value } \\
\text { (kPa) }\end{array}$ & $\begin{array}{l}\text { Ratio of Error } \\
\text { Value to } \\
\text { Experimental } \\
\text { Result (\%) }\end{array}$ \\
\hline \multirow{12}{*}{ Sample 2\# } & \multirow{12}{*}{200} & 0.05 & 283.7 & 240.62 & -43.08 & -15.19 \\
\hline & & 0.1 & 282.6 & 257.37 & -25.23 & -8.93 \\
\hline & & 0.15 & 282.6 & 267.84 & -14.76 & -5.22 \\
\hline & & 0.2 & 285.9 & 275.60 & -10.30 & -3.60 \\
\hline & & 0.3 & 289.75 & 287.05 & -2.70 & -0.93 \\
\hline & & 0.4 & 289.75 & 295.56 & 5.81 & 2.01 \\
\hline & & 0.5 & 291.9 & 302.40 & 10.50 & 3.60 \\
\hline & & 0.6 & 294.1 & 308.16 & 14.06 & 4.78 \\
\hline & & 0.7 & 282.05 & 313.15 & 31.10 & 11.03 \\
\hline & & 0.8 & 286.95 & 317.56 & 30.61 & 10.67 \\
\hline & & 0.9 & 282.6 & 321.53 & 38.93 & 13.77 \\
\hline & & 1.0 & 296.85 & 325.14 & 28.29 & 9.53 \\
\hline \multirow{12}{*}{ Sample 3\# } & \multirow{12}{*}{200} & 0.05 & 229.5 & 240.62 & 11.12 & 4.84 \\
\hline & & 0.1 & 236.05 & 257.37 & 21.32 & 9.03 \\
\hline & & 0.15 & 249.2 & 267.84 & 18.64 & 7.48 \\
\hline & & 0.2 & 249.2 & 275.60 & 26.40 & 10.59 \\
\hline & & 0.3 & 253.05 & 287.05 & 34.00 & 13.44 \\
\hline & & 0.4 & 252.5 & 295.56 & 43.06 & 17.05 \\
\hline & & 0.5 & 254.15 & 302.40 & 48.25 & 18.99 \\
\hline & & 0.6 & 256.35 & 308.16 & 51.81 & 20.21 \\
\hline & & 0.7 & 259.05 & 313.15 & 54.10 & 20.88 \\
\hline & & 0.8 & 270.55 & 317.56 & 47.01 & 17.38 \\
\hline & & 0.9 & 266.2 & 321.53 & 55.33 & 20.78 \\
\hline & & 1.0 & 266.2 & 325.14 & 58.94 & 22.14 \\
\hline \multirow{3}{*}{ Sample 4\# } & \multirow{3}{*}{200} & 0.1 & 351.35 & 367.17 & 15.82 & 4.50 \\
\hline & & 0.5 & 368.35 & 444.89 & 76.54 & 20.78 \\
\hline & & 1.0 & 376.05 & 487.08 & 111.03 & 29.52 \\
\hline \multirow{7}{*}{ Sample 5\# } & \multirow{7}{*}{100} & 0.033 & 116.788 & 119.60 & 2.81 & 2.40 \\
\hline & & 0.05 & 116.664 & 124.50 & 7.84 & 6.72 \\
\hline & & 0.083 & 114.876 & 130.82 & 15.94 & 13.88 \\
\hline & & 0.1 & 123.496 & 133.24 & 9.74 & 7.89 \\
\hline & & 0.13 & 126.148 & 136.75 & 10.60 & 8.40 \\
\hline & & 0.2 & 133.58 & 142.78 & 9.20 & 6.89 \\
\hline & & 0.25 & 139.364 & 146.04 & 6.68 & 4.79 \\
\hline
\end{tabular}

\section{References}

1. Goodman, R.E.; Taylor, R.L.; Brekke, T.A. A model for the mechanics of jointed rock. J. Soil Mech. Found. Div. 1968, 94, 637-659.

2. Hoek, E. Strength of jointed rock masses. Geotechnique 1983, 33, 187-223. [CrossRef]

3. Barton, N.; Bandis, S.; Bakhtar, K. Strength, deformation and conductivity coupling of rock joints. Int. J. Rock Mech. Min. Sci. Geomech. Abstr. 1985, 22, 121-140. [CrossRef]

4. Saroglou, C.; Qi, S.W.; Guo, S.F.; Wu, F.Q. ARMR, a new classification system for the rating of anisotropic rock masses. Bull. Eng. Geol. Environ. 2018, 78, 3611-3626. [CrossRef]

5. Plesha, M.E. Constitutive models for rock discontinuities with dilatancy and surface degradation. Int. J. Numer. Anal. Methods Geomech. 1987, 11,345-362. [CrossRef]

6. Grasselli, G. Shear Strength of Rock Joints Based on Quantified Surface Description. Ph.D. Thesis, Swiss Federal Institute of Technology, Zürich, Switzerland, 2001.

7. Guo, S.F.; Qi, S.W. Numerical study on progressive failure of hard rock samples with an unfilled undulate joint. Eng. Geol. 2015, 193, 173-182. [CrossRef] 
8. Bahaaddini, M.; Hagan, P.C.; Mitra, R.; Khosravi, M.H. Experimental and numerical study of asperity degradation in the direct shear test. Eng. Geol. 2016, 204, 41-52. [CrossRef]

9. Guo, S.F.; Qi, S.W.; Zhan, Z.F.; Zheng, B.W. Plastic-strain-dependent strength model to simulate the cracking process of brittle rocks with an existing non-persistent joint. Eng. Geol. 2017, 231, 114-125. [CrossRef]

10. Qi, S.W.; Xu, Q.; Lan, H.X.; Zhang, B.; Liu, J.Y. Spatial distribution analysis of landslides triggered by 2008.5 .12 Wenchuan Earthquake, China. Eng. Geol. 2010, 116, 95-108. [CrossRef]

11. Qi, S.W.; Xu, Q.; Zhang, B.; Zhou, Y.D.; Lan, H.X.; Li, L.H. Source characteristics of long runout rock avalanches triggered by the 2008 Wenchuan earthquake, China. J. Asian Earth Sci. 2011, 40, 896-906. [CrossRef]

12. Qi, S.W.; Lan, H.X.; Dong, J.Y. An analytical solution to slip buckling slope failure triggered by earthquake. Eng. Geol. 2015, 194, 4-11. [CrossRef]

13. Huang, X.L.; Qi, S.W.; Guo, S.F.; Dong, W.L. Experimental study of ultrasonic waves propagating through a rock mass with a single joint and multiple parallel joints. Rock Mech. Rock Eng. 2014, 47, 549-559. [CrossRef]

14. Huang, X.L.; Qi, S.W.; Williams, A.; Zou, Y.; Zheng, B.W. Numerical simulation of stress wave propagating through filled joints by particle model. Int. J. Solids Struct. 2015, 69, 23-33. [CrossRef]

15. Huang, X.L.; Qi, S.W.; Xia, K.W.; Shi, X.S. Particle crushing of a filled fracture during compression and its effect on stress wave propagation. J. Geophys. Res. Solid Earth 2018, 123, 5559-5587. [CrossRef]

16. Muralha, J.; Grasselli, G.; Tatone, B.; Blümel, M.; Chryssanthakis, P.; Jiang, Y.J. ISRM suggested method for laboratory determination of the shear strength of rock joints: Revised version. Rock Mech. Rock Eng. 2014, 47, 291-302. [CrossRef]

17. Qi, S.W.; Macciotta, R.; Shou, K.J.; Saroglou, C. Preface to the Special Issue on "Advances in Rock Mass Engineering Geomechanics". Eng. Geol. 2020, 272, 105642. [CrossRef]

18. Patton, F.D. Multiple Modes of Shear Failure in Rock and Related Materials. Ph.D. Thesis, University of IIIinois, Urbana, IL, USA, 1966.

19. Patton, F.D. Multiple modes of shear failure in rock. In Proceedings of the 1st Congress of International Society for Rock Mechanics, Lisbon, Portugal, 25 September-1 October 1966; pp. 509-513.

20. Ladanyi, B.; Archambault, G. Simulation of shear behavior of a jointed rock mass. In Proceedings of the 11th Symposium on Rock Mechanics: Theory and Practice, Berkeley, CA, USA, 16-19 June 1969; pp. 105-125.

21. Barton, N. Review of a new shear-strength criterion for rock joints. Eng. Geol. 1973, 7, 287-332. [CrossRef]

22. Jing, L.; Nordlund, E.; Stephansson, O. An experimental study on the anisotropy and stress-dependency of the strength and deformability of rock joints. Int. J. Rock Mech. Min. Sci. Geomech. Abstr. 1992, 29, 535-542. [CrossRef]

23. Huang, X.; Haimson, B.C.; Plesha, M.E.; Qiu, X. An investigation of the mechanics of rock joints-Part I. Laboratory investigation. Int. J. Rock Mech. Min. Sci. Geomech. Abstr. 1993, 30, 257-269. [CrossRef]

24. Qiu, X.; Plesha, M.E.; Huang, X.; Haimson, B.C. An investigation of the mechanics of rock joints-Part II. Analytical investigation. Int. J. Rock Mech. Min. Sci. Geomech. Abstr. 1993, 30, 271-287. [CrossRef]

25. Kulatilake, P.; Shou, G.; Huang, T.H.; Morgan, R.M. New peak shear strength criteria for anisotropic rock joints. Int. J. Rock Mech. Min. Sci. Geomech. Abstr. 1995, 32, 673-697. [CrossRef]

26. Zhao, J. A new JRC-JMC shear strength criterion for rock joint. Chin. J. Rock Mech. Eng. 1998, 17, 349-357. (In Chinese)

27. Homand, F.; Belem, T.; Souley, M. Friction and degradation of rock joint surfaces under shear loads. Int. J. Numer. Anal. Methods Geomech. 2001, 25, 973-999. [CrossRef]

28. Grasselli, G.; Egger, P. Constitutive law for the shear strength of rock joints based on three-dimensional surface parameters. Int. J. Rock Mech. Min. Sci. 2003, 40, 25-40. [CrossRef]

29. Xia, C.C.; Tang, Z.C.; Xiao, W.M.; Song, Y.L. New peak shear strength criterion of rock joints based on quantified surface description. Rock Mech. Rock Eng. 2014, 47, 387-400. [CrossRef]

30. Tse, R.; Cruden, D.M. Estimating joint roughness coefficients. Int. J. Rock Mech. Min. Sci. Geomech. Abstr. 1979, 16, 303-307. [CrossRef]

31. Maerz, N.H.; Franklin, J.A.; Bennett, C.P. Joint roughness measurement using shadow profilometry. Int. J. Rock Mech. Min. Sci. Geomech. Abstr. 1990, 27, 329-343. [CrossRef]

32. Beer, A.J.; Stead, D.; Coggan, J.S. Technical note estimation of the joint roughness coefficient (JRC) by visual comparison. Rock Mech. Rock Eng. 2002, 35, 65-74. [CrossRef]

33. Jang, H.S.; Kang, S.S.; Jang, B.A. Determination of joint roughness coefficients using roughness parameters. Rock Mech. Rock Eng. 2014, 47, 2061-2073. [CrossRef] 
34. Li, Y.R.; Huang, R.Q. Relationship between joint roughness coefficient and fractal dimension of rock fracture surfaces. Int. J. Rock Mech. Min. Sci. 2015, 75, 15-22. [CrossRef]

35. Zheng, B.W.; Qi, S.W. A new index to describe joint roughness coefficient (JRC) under cyclic shear. Eng. Geol. 2016, 212, 72-85. [CrossRef]

36. Bao, H.; Zhang, G.B.; Lan, H.X.; Yan, C.G.; Xu, J.B.; Xu, W. Geometrical heterogeneity of the joint roughness coefficient revealed by 3D laser scanning. Eng. Geol. 2020, 265, 105415. [CrossRef]

37. Barton, N.; Choubey, V. The shear strength of rock joints in theory and practice. Rock Mech. 1977, 10, 1-54. [CrossRef]

38. International society for rockmechanics commission on standardization of laboratory and field tests. Suggested methods for the quantitative description of discontinuities in rock masses. Int. J. Rock Mech. Min. Sci. Geomech. Abstr. 1978, 15, 319-368.

39. Bandis, S.; Lumsden, A.; Barton, N. Experimental studies of scales effects on the shear behaviour of rock joints. Int. J. Rock Mech. Min. Sci. Geomech. Abstr. 1981, 18, 1-21. [CrossRef]

40. Barton, N.; Bandis, S. Effects of block size on the shear behavior of jointed rock. In Proceedings of the $23 \mathrm{rd}$ U.S Symposium on Rock Mechanics, Berkeley, CA, USA, 25-27 August 1982; pp. 739-760.

41. Cunha, A.P. Scale effects in rock mechanics. In Proceedings of the 1st International Workshop on Scale Effects in Rock Masses, Loen, Norway, 7-8 June 1990; pp. 3-27.

42. Castelli, M.; Savia, S.; Zanineti, A. Experimental evaluation of scale effect on the mechanical behavior of rock joints. In Proceedings of the International Eurock Symposium, Espoo, Finland, 4-7 June 2001; pp. 205-210.

43. Du, S.G.; Hu, Y.J.; Hu, X.F. Measurement of joint roughness coefficient by using profilograph and roughness ruler. J. Earth Sci. 2009, 20, 890-896. [CrossRef]

44. Vallier, F.; Mitani, Y.; Boulon, M.; Esaki, T.; Pellet, F. A new shear model for accounting scale effect in rock joints behavior. Rock Mech. Rock Eng. 2010, 43, 581-595. [CrossRef]

45. Chen, S.J.; Zhu, W.C.; Yu, Q.L.; Liu, X.G. Characterization of anisotropy of joint surface roughness and aperture by variogram approach based on digital image processing technique. Rock Mech. Rock Eng. 2015, 49, 855-876. [CrossRef]

46. Song, L.B.; Jiang, Q.; Li, Y.H.; Yang, C.X.; Ran, S.G.; Wang, B.L.; Liu, T. Description of discontinuities morphology based on shear behavior. Rock Soil Mech. 2017, 38, 525-533. (In Chinese)

47. Schneider, H.J. The time dependence of friction of rock joints. Bull. Int. Assoc. Eng. Geol. 1977, 16, $235-239$. [CrossRef]

48. Dieterich, J.H. Time-dependent friction and the mechanics of stick-slip. Pure Appl. Geophys. 1978, 116, 790-806. [CrossRef]

49. Crawford, A.M.; Curran, J.H. The influence of shear velocity on the frictional resistance of rock discontinuities. Int. J. Rock Mech. Min. Sci. Geomech. Abstr. 1981, 18, 505-515. [CrossRef]

50. Gillette, D.R.; Sture, S.; Ko, H.K.; Gould, M.C.; Scott, G.A. Dynamic behavior of rock joints. In Proceedings of the 24th US Symposium on Rock Mechanics, College Station, TX, USA, 20-23 June 1983; pp. 163-179.

51. Li, H.B.; Feng, H.P.; Liu, B. Study on strength behaviors of rock joints under different shearing deformation velocities. Chin. J. Rock Mech. Eng. 2006, 25, 2435-2440. (In Chinese)

52. Atapour, H.; Moosavi, M. The influence of shearing velocity on shear behavior of artificial joints. Rock Mech. Rock Eng. 2014, 47, 1745-1761. [CrossRef]

53. Wang, G.; Zhang, X.P.; Jiang, Y.J.; Zhang, Y.Z. New shear strength criterion for rough rock joints considering shear velocity. Chin. J. Geotech. Eng. 2015, 37, 1399-1404. (In Chinese)

54. Zheng, B.W.; Qi, S.W.; Zhan, Z.F.; Zou, Y.; Zhang, S.S. Effect of shear rate on the strength characteristics of rock joints. J. Earth Sci. Environ. 2015, 37, 101-110. (In Chinese)

55. Mehrishal, S.; Sharifzadeh, M.; Shahriar, K.; Song, J.J. An experimental study on normal stress and shear rate dependency of basic friction coefficient in dry and wet limestone joints. Rock Mech. Rock Eng. 2016, 49, 4607-4629. [CrossRef]

56. Tang, Z.C.; Wong, L.Y.N. Influences of normal loading rate and shear velocity on the shear behavior of artificial rock joints. Rock Mech. Rock Eng. 2016, 49, 2165-2172. [CrossRef]

57. Meng, F.Z.; Wong, L.N.Y.; Zhou, H.; Wang, Z.Q. Comparative study on dynamic shear behavior and failure mechanism of two types of granite joint. Eng. Geol. 2018, 245, 356-369. [CrossRef]

58. Qi, S.W.; Zheng, B.W.; Wu, F.Q.; Huang, X.L.; Zhan, Z.F.; Zou, Y. A Test System and Test Method for the Properties of Discontinuities. China Patent ZL201410078860.7, 6 July 2016. (In Chinese). 
59. Qi, S.W.; Zheng, B.W.; Wu, F.Q.; Huang, X.L.; Guo, S.F.; Zhan, Z.F.; Zou, Y.; Barla, G. A new dynamic direct shear testing device on rock joints. Rock Mech. Rock Eng. 2020. (under review).

60. Hu, Y.X.; Liu, S.C.; Dong, W. Earthquake Engineering; CRC Press: London, UK, 1996.

61. Zhang, Q.B.; Zhao, J. A review of dynamic experimental techniques and mechanical behaviour of rock materials. Rock Mech. Rock Eng. 2014, 47, 1411-1478. [CrossRef] 